\title{
OS GASTOS SOCIAIS MUNICIPAIS E OS INDICADORES DE QUALIDADE DE VIDA DOS MUNICÍPIOS GAÚCHOS: O CASO DO COREDE METROPOLITANO DELTA DO JACUÍ (1991-2008)
}

\author{
Wagner Santana de Fraga ${ }^{1}$ \\ Angélica Massuquetti ${ }^{2}$ \\ Luciano Feltrin ${ }^{3}$ \\ Gabriela da Silva Schumacher ${ }^{4}$
}

RESUMO: O objetivo do estudo foi analisar como os gastos sociais dos municípios que integram o COREDE Metropolitano Delta do Jacuí (Rio Grande do Sul) influenciaram na evolução de seus indicadores socioeconômicos no período 1991-2008. Para tanto, foram analisados os gastos públicos, no âmbito dos municípios do COREDE, com assistência social, saúde, saneamento, educação e cultura, verificando sua relação com a variação do IDESE dos municípios. Como resultados, foi possível observar que os municípios que apresentaram maior expansão do gasto público e do PIB não estão, necessariamente, entre aqueles que possuem os melhores índices de desenvolvimento humano. Portanto, apesar de terem despendido um montante maior de recursos para as áreas sociais e das melhorias obtidas nos seus índices, principalmente na dimensão educação, as demais dimensões analisadas não demonstram sensibilidade somente às variações dos gastos públicos e dos PIB's municipais.

Palavras-chave: Desenvolvimento Socioeconômico. Gastos Públicos. Gastos Sociais.

ABSTRACT: The paper analyses how the social expenditures of the towns that belong to the COREDE Metropolitano Delta do Jacuí (Rio Grande do Sul) affected the evolution of socioeconomic indicators in the period 1991-2008. Public expenditures of the towns belonging to the COREDES were examined focusing on social care, health, sanitation, education and culture, comparing with the variation of IDESE of these towns. The results show that the towns with both higher expansion of public expenditures and GDP were not necessarily those with the better human development indices. Thus, despite having spent a higher amount of resources to social areas and the improvement in those indicators, especially on Education, the remaining indicators did not respond accordingly to the increases on public expenditures and the town's GDPs.

Key-words: Socioeconomic Development. Public Expenditures. Social Expenditures.

\footnotetext{
${ }^{1}$ Economista pelo Curso de Ciências Econômicas da Universidade do Vale do Rio dos Sinos (UNISINOS) e Secretário da Prefeitura Municipal de Gravataí (PMG). E-mail: wagnerdefraga @ hotmail.com.

${ }^{2}$ Professora e Pesquisadora do Programa de Pós-Graduação em Economia (PPGE) da Universidade do Vale do Rio dos Sinos (UNISINOS). E-mail: angelicam@ unisinos.br.

${ }^{3}$ Professor do Curso de Ciências Econômicas da Universidade do Vale do Rio dos Sinos (UNISINOS) e Economista do Banco Regional de Desenvolvimento do Extremo Sul (BRDE). E-mail: luciano.feltrin@brde.com.br.

${ }^{4}$ Economista pelo Curso de Ciências Econômicas da Universidade do Vale do Rio dos Sinos (UNISINOS). Email: gabriela_schumacher@yahoo.com.br.
}

Recebido em: 21/12/2011

Aceito em: 01/03/2012 


\section{INTRODUÇÃO}

Na tentativa de implementar políticas públicas que possibilitem o desenvolvimento socioeconômico de sua população, por meio dos municípios, dos estados e também pela própria União, o governo federal busca a construção de uma política fiscal que desempenhe efetivamente suas três funções fundamentais: alocativa, distributiva e estabilizadora (GIAMBIAGI; ALÉM, 2000). Desta forma, o governo federal tem procurado maximizar os resultados dos programas sociais no sentido de atingir o conjunto de metas pactuadas (Objetivos de Desenvolvimento do Milênio) pelos países membros da Organização das Nações Unidas (ONU), cuja finalidade é a busca pelo real desenvolvimento socioeconômico de sua população.

A importância de perceber se os tributos arrecadados pelo poder público para o custeio de suas atividades, bem como para a realização dos seus investimentos, estão retornando a seus contribuintes por meio da implementação de políticas públicas que gerem efeitos na economia, principalmente com os impactos no crescimento e no desenvolvimento socioeconômico, tem se constituído cada vez mais numa preocupação permanente dos gestores públicos. Estas tentativas buscam identificar se tais políticas construídas para o cumprimento das metas pactuadas são ferramentas eficazes na melhoria do nível socioeconômico da sociedade, ou seja, se são resolutivas na busca da redução da pobreza e se proporcionam melhorias nas condições de vida da população.

Os indicadores socioeconômicos, projetados tanto pela ONU quanto por outras instituições, demonstram a necessidade de informações e de metodologias que apurem o nível de desenvolvimento social e humano. No entanto, observa-se que tais índices não oferecem respostas específicas a respeito do desempenho dos gestores e da avaliação do impacto dos investimentos sociais e, além disto, não permitem identificar a importância e a contribuição de cada área no desenvolvimento social. Neste sentido, é fundamental a realização de estudos que analisem o impacto dos gastos públicos no desenvolvimento socioeconômico, contribuindo para aumentar a eficiência das políticas e a alocação de recursos públicos.

$\mathrm{Na}$ atual administração pública, os gestores buscam cada vez mais indicadores que possibilitem a mensuração de seu desempenho em relação à eficiência da aplicação dos recursos públicos. Esta é uma preocupação permanente por parte dos gestores públicos e necessária para que as ações dos governos nacionais, estaduais e municipais correspondam ao aumento das necessidades da população. Sendo assim, o objetivo do presente artigo 
consiste em analisar se os gastos sociais ${ }^{5}$ dos municípios que integram o Conselho Regional de Desenvolvimento (COREDE) ${ }^{6}$ Metropolitano Delta do Jacuí influenciaram no desempenho e na evolução de seus indicadores socioeconômicos no período 1991-2008. Para tanto, analisou-se os gastos públicos, no âmbito dos municípios do COREDE, com assistência social, saúde, saneamento, educação e cultura, verificando seu efeito sobre a variação do Índice de Desenvolvimento Socioeconômico (IDESE) dos municípios. O COREDE Metropolitano Delta do Jacuí é um dos principais pólos urbanos de serviços e de industrialização do estado do Rio Grande do Sul.

Para o desenvolvimento deste artigo, além desta introdução, o estudo está organizado em mais quatro seções. $\mathrm{Na}$ segunda, aborda-se a relação entre políticas públicas, gastos sociais e desenvolvimento socioeconômico. Na terceira, expõe-se a metodologia empregada e descreve-se o COREDE Metropolitano Delta do Jacuí. A quarta seção apresenta os resultados do estudo. E, por fim, na quinta seção são apresentadas as considerações finais.

\section{POLÍticas públicas, gastos SOCIAIS E DESENVOLVIMENTO SOCIOECONÔMICO}

Inúmeros debates têm sido travados em torno da carga tributária brasileira e de que maneira estes recursos são aplicados pelos municípios, estados e União, ou seja, de que forma tais recursos retornam ao conjunto da população por meio de serviços públicos, de investimentos em infraestrutura e de políticas sociais que permitam uma adequada redistribuição destes tributos (REZENDE et al., 2005). As políticas de desenvolvimento econômico, implementadas no Brasil, contudo, sempre foram conservadoras, o que proporcionou o aumento da concentração de renda, ocasionando desigualdade de renda e exclusão social e cultural.

A década de 1920, no Brasil, foi marcada pelo início da política de assistência social. Naquele período, surgiram as primeiras legislações e o Sistema Previdenciário brasileiro, mas foi no auge do governo populista de Getúlio Vargas que teve início uma

\footnotetext{
${ }^{5}$ Segundo Fernandes et al. (1998, p. 12), "Gasto social é aquele gasto voltado para a melhoria, a curto e longo prazo, das condições de vida da população".

${ }^{6}$ A divisão do estado em Conselhos Regionais de Desenvolvimento tem como objetivo a promoção do desenvolvimento regional, harmônico e sustentável por meio da integração dos recursos e das ações governamentais na região, visando a melhoria da qualidade de vida da população, a distribuição equitativa da riqueza produzida, bem como o estímulo à permanência do homem em sua região e à preservação do meio ambiente (SEPLAG, 2012).
} 
série de mudanças significativas na área social (criação das leis trabalhistas, sindicatos, dentre outras). A partir de 1964, houve expressiva mudança na forma de industrialização: as pequenas indústrias de vários segmentos se consolidaram e se transformaram em parques industriais com forte presença do Estado nas atividades produtivas, materializando o modelo de desenvolvimento econômico amparado na ampliação do acesso da sociedade brasileira ao consumo. A década de 1970, apesar da continuidade do regime militar, foi marcada por mudanças estruturais importantes e também por avanços sociais significativos, tais como: melhoria do nível de vida e redução da pobreza, obrigatoriedade de educação básica, atenção primária à saúde etc. (REZENDE et al., 2005).

Apesar dos anos 1980 terem sido caracterizados como a década perdida devido aos períodos de recessão e de hiperinflação no Brasil, e em outras partes do mundo, ocorreram grandes avanços no campo político, com o surgimento da Nova República. Este período revelou uma população mais engajada e consciente ${ }^{7}$, culminando com a nova Constituição Federal, em 1988. A partir do processo de descentralização administrativa e política da gestão pública, desencadeado após a Constituição de 1988, alguns avanços podem ser considerados como positivos, principalmente no que diz respeito à aproximação da população com os governos locais que implementam as ações sociais. Tal descentralização possibilitou a diminuição de custos e o aumento da eficiência na realização das políticas públicas, que passaram a atuar em consonância com as realidades locais. Esta aproximação do governo com a população promove uma maior participação da sociedade como parceira na administração e agente fiscalizador (REZENDE et al., 2005). Mesmo com a maior descentralização proporcionada a partir da Constituição de 1988, que permitiu que os municípios passassem a ser responsáveis pela realização de um conjunto de políticas públicas, aumentando para isto as transferências federais para os municípios, contudo, estas transformações não foram suficientes para diminuir, nas proporções desejadas, as históricas desigualdades existentes na sociedade brasileira (OLIVEIRA, 1999).

A partir do momento em que a população se conscientiza e exige do poder público (federal, estadual e municipal) e de outras instituições (universidades, organizações não

\footnotetext{
${ }^{7}$ A maior interação entre governantes e população, característica da sociedade atual (OSBONE; GAEBLER, 1994), é observada no Brasil em todos os campos: político (impeachment, instauração de Comissão Parlamentar de Inquérito - CPI), empresarial (apoio à cultura, educação, esporte etc.), governamental (valorização do servidor, aumento quantitativo nos investimentos sociais) e comunitário (ampliação da democracia participativa). $\mathrm{O}$ aumento do interesse da população em participar da vida política e, em especial, de temas ligados à área social possibilita ao cidadão entender melhor o papel do Estado como agente arrecadador de tributos e distribuidor destes por meio de programas de saúde, de educação, de habitação etc. Esta conscientização da sociedade tem provocado, também, mudanças comportamentais na política, exigindo dos gestores públicos maior controle e transparência dos recursos públicos (BISPO, 1999).
} 
governamentais etc.) uma ação cada vez mais voltada para a dimensão social, é necessário o maior comprometimento da esfera pública na implementação das políticas sociais (SOUZA, 1997). Sob esta perspectiva e com o aumento da conscientização sobre o tema social, surgem talvez as primeiras necessidades de transparência e a efetiva cobrança por parte da população.Neste contexto, novas legislações foram aprovadas pelo Congresso Nacional, e sancionadas pela Presidência da República, com o intuito de controlar as despesas públicas, bem como de tornar mais transparente a sua gestão. A Lei de Responsabilidade Fiscal, Lei n. 101, de 15 de dezembro de 2000, por exemplo, agrega novas formas de transparência, com a criação de relatórios sociais e fiscais de forma simplificada, que leva à contenção de gastos e à adequação das receitas com as despesas do setor público. Esta Lei conta com a contabilidade pública, que procura, com o auxílio da legislação vigente, atingir seus objetivos de registro, controle, transparência, prestação de contas e divulgação de informações (REZENDE et al., 2005).

O Estado, além de ser responsável pela implementação de políticas públicas que possibilitam o desenvolvimento socioeconômico de sua população, por meio dos municípios, dos estados e também pela própria União, tem como atribuição realizar o papel de arrecadador de recursos financeiros e de promotor da satisfação das necessidades da população (GIAMBIAGI; ALÉM, 2000; GIACOMONI, 1998). Atualmente, é sabido que o administrador público precisa ir além de apenas gerir os recursos sobre sua tutela, já que, ao contrário da empresa privada, seus objetivos não visam a obtenção de lucros, mas a qualidade de vida da população (SLOMSKI, 1999).

Para verificar a efetividade e a eficiência das políticas públicas implementadas pelos municípios a partir da consolidação do processo de descentralização políticoadministrativa verificado com a Constituição de 1988, portanto, surge cada vez mais a necessidade de estudos acercados gastos sociais municipais.

\section{MÉTODOS E PROCEDIMENTOS}

\subsection{Definição dos dados}

Para verificar a evolução do desenvolvimento socioeconômico dos municípios integrantes do COREDE Metropolitano Delta do Jacuí, no período 1991-2008, é utilizado o IDESE. Este índice passou a ser calculado pela Fundação de Economia e Estatística (FEE) para os municípios, desde 1991, e para os 28 COREDEs, desde 2000, e é 
semelhante ao Índice de Desenvolvimento Humano Municipal (IDH-M), contudo, foi desenvolvido somente para os municípios gaúchos, não permitindo comparações com o conjunto dos municípios brasileiros, e inclui saneamento e domicílio. As dimensões consideradas pelo IDESE são educação, renda $^{8}$, saneamento e domicílios e saúde, sendo compostas de grupos de indicadores selecionados que, após serem transformados em índices, são agregados com pesos específicos, definidos pela equipe técnica, resultando no índice do respectivo bloco. O IDESE varia entre 0 e 1 , sendo 0 quando não há desenvolvimento e 1 quando há desenvolvimento total, e divide os COREDES e os municípios em grupos com baixo desenvolvimento (de 0 a 0,499 ), médio desenvolvimento (de 0,500 e 0,799) e, por fim, alto desenvolvimento (acima de 0,800) (FEE, 2012c).

Além do IDESE, analisa-se a evolução do Produto Interno Bruto (PIB) dos municípios que integram o COREDE Metropolitano Delta do Jacuí a partir dos dados disponibilizados no IPEADATA, base de dados do Instituto de Pesquisa Econômica Aplicada (IPEA), no período 1985-2008. Em relação aos gastos sociais municipais, os dados analisados foram obtidos em Rückert et al. (2008), para os anos de 1995 a 2003, e no Tribunal de Contas do Estado do Rio Grande do Sul (TCE-RS), para o período 2004-2008. Por fim, o número de alunos matriculados nos municípios do COREDE, nos anos de 2000 e de 2008, foiobtido no Instituto Nacional de Estudos e Pesquisas Educacionais Anísio Teixeira (INEP).

\subsection{Definição da área de estudo}

O COREDE Metropolitano Delta do Jacuí é um dos principais pólos urbanos gaúchos de serviços e de industrialização. Situado na região leste do estado, este Conselho possui um contingente populacional de 2.420.262 habitantes (2010) e uma área de 5.652,1 $\mathrm{km}^{2}$, com uma densidade demográfica de 428,2 hab./ $\mathrm{km}^{2}$ (2010), e sua abrangência territorial compreende, além de Porto Alegre, capital do estado do Rio Grande do Sul, os municípios de: Alvorada, Cachoeirinha, Eldorado do Sul, Glorinha, Gravataí, Guaíba, Triunfo, Santo Antônio da Patrulha e Viamão (FEE, 2012a).

O COREDE Metropolitano Delta do Jacuí, juntamente com os COREDEs Vale do Rio dos Sinos e Serra, correspondem a $52 \%$ do Valor Adicionado Bruto a preços básicos

\footnotetext{
${ }^{8}$ A dimensão renda, do IDESE, é formada pelos indicadores Produto Interno Bruto per capita (PIBpc) e Valor Adicionado Bruto per capita (VABpc) do comércio, alojamento e alimentação. Por este motivo, o PIBpc não foi analisado individualmente na seção 4.
} 
(VABpb) do estado (2009).Juntas, estas três regiões perfazem $61 \%$ do VABpb industrialdo Rio Grande do Sul (2009), possuindo um perfil produtivo bem distribuído nos mais variados segmentos. O COREDE Metropolitano Delta do Jacuí representa 25\% do VABpb industrial do estado, devendo ser considerada a grande contribuição da concentração industrial em torno do eixo Porto Alegre-Caxias do Sul. O PIB desta região, em 2009, representou 53\% do PIB do estado, totalizando $\mathrm{R} \$$ (mil) 114.400.795,60. O PIB do COREDE Metropolitano Delta do Jacuí representou 27\% do PIB estadual, com valor de R\$ (mil) 58.326.590,31. Já o PIB per capita do COREDE Metropolitano Delta do Jacuí, no mesmo período, foi de $R \$ 23.322$, enquanto no estado alcançou apenas o valor de $R \$$ 19.778 (FEE, 2012b).

Além de ser um dos COREDEs com maior representatividade econômica do estado, o Metropolitano Delta do Jacuí apresenta indicadores de desenvolvimento socioeconômico iguais ou superiores aos resultados verificados pelo Rio Grande do Sul, onde a taxa de analfabetismo é de 2,96\% (2010) e o coeficiente de mortalidade infantil para cada mil nascidos vivos é de 10,99 óbitos (2010), resultados melhores do que os apresentados pelo Rio Grande do Sul, onde, no mesmo período, a taxa de analfabetismo foi de $4,53 \%$ e cujo coeficiente de mortalidade infantil ficou em 11,18 óbitos para cada mil nascidos vivos. Já a expectativa de vida ao nascer, em 2000, para o COREDE Metropolitano Delta do Jacuí, foi de 72,07 anos, enquanto no estado foi de 72,05 anos (FEE, 2012a).

A Tabela 1 tem como finalidade proporcionar uma visão introdutória dos municípios que integram o COREDE Metropolitano Delta do Jacuí, mostrando as suas principais características socioeconômicas.

Tabela 1: Resumo Estatístico dos Municípios Integrantes do COREDE Metropolitano Delta do Jacuí - 2000/2009/2010

\begin{tabular}{|c|c|c|c|c|c|c|c|c|}
\hline Município & $\begin{array}{c}\text { População } \\
\text { Total } \\
\text { (2010), em } \\
\text { habitantes }\end{array}$ & $\begin{array}{c}\text { Área } \\
(2010), \\
\text { em km² }\end{array}$ & $\begin{array}{c}\text { Densidade } \\
\text { Demográfica } \\
(2010), \text { em } \\
\text { hab./km² }\end{array}$ & $\begin{array}{c}\text { Taxa de } \\
\text { Analfabetismo } \\
\text { (2010), em \% }\end{array}$ & $\begin{array}{c}\text { Expectativa } \\
\text { de Vida ao } \\
\text { Nascer } \\
(2000), \text { em } \\
\text { anos }\end{array}$ & $\begin{array}{c}\text { Coeficiente de } \\
\text { Mortalidade } \\
\text { Infantil (2010), } \\
\text { por mil } \\
\text { nascidos vivos }\end{array}$ & $\begin{array}{c}\text { PIB per capita } \\
(2009), \\
\text { R\$/pessoa/ano }\end{array}$ & $\begin{array}{l}\text { Data de } \\
\text { Criação }\end{array}$ \\
\hline Alvorada & 195.673 & 70,80 & $2.763,3$ & 3,93 & 69,99 & 11,13 & 5.553 & $17 / 09 / 1965$ \\
\hline Cachoeirinha & 118.278 & 43,80 & $2.702,5$ & 2,94 & 72,60 & 12,54 & 27.305 & $09 / 11 / 1965$ \\
\hline $\begin{array}{c}\text { Eldorado do } \\
\text { Sul } \\
\end{array}$ & 34.343 & 509,70 & 67,4 & 4,18 & 73,60 & 9,45 & 19.342 & 08/06/1988 \\
\hline Glorinha & 6.891 & 323,60 & 21.3 & 8,08 & 73,60 & 28,99 & 25.053 & $04 / 05 / 1988$ \\
\hline Gravataí & 255.660 & 463,80 & 551,3 & 3,20 & 73,60 & 10,96 & 20.890 & $11 / 06 / 1880$ \\
\hline Guaíba & 95.204 & 377,00 & 252,5 & 3,83 & 71,32 & 7,99 & 20.136 & $14 / 10 / 1926$ \\
\hline Porto Alegre & 1.409 .351 & 496,80 & $2.836,7$ & 2,28 & 71,59 & 10,53 & 26.312 & $23 / 08 / 1808$ \\
\hline $\begin{array}{c}\text { Santo } \\
\text { Antônio da } \\
\text { Patrulha }\end{array}$ & 39.685 & $1.048,90$ & 37,8 & 9,05 & 72,49 & 15,63 & 12.560 & $07 / 10 / 1809$ \\
\hline Triunfo & 25.793 & 823,40 & 31,3 & 6,51 & 71,46 & 20,51 & 211.965 & $25 / 10 / 1831$ \\
\hline Viamão & 239.384 & $1.494,30$ & 160,2 & 4,19 & 75,02 & 12,73 & 7.050 & $11 / 06 / 1880$ \\
\hline COREDE & 2.420 .262 & $5.652,1$ & 428,2 & 2,96 & 72,07 & 10,99 & 23.322 & - \\
\hline Estado & 10.693 .929 & $281.748,5$ & 38,0 & 4,53 & 72,05 & 11,18 & 19.778 & - \\
\hline
\end{tabular}

Fonte: Elaboração própria a partir de FEE (2012a; 2012b). 
Os municípios que compõem o COREDE Metropolitano Delta do Jacuí possuem diferentes níveis de desenvolvimento socioeconômico, sendo necessária uma análise mais detalhada dos indicadores de desenvolvimento humano dos integrantes deste Conselho com o intuito de identificar quais são as áreas que necessitam de um maior aporte de recursos públicos. Para tanto, a próxima seção será destinada a analisar, individualmente, como foi o avanço socioeconômico de cada município e os impactos gerados pelas políticas públicas.

\section{APRESENTAÇÃO E ANÁLISE DOS DADOS}

\subsection{Indicadores socioeconômicos dos COREDEs}

A partir do IDESE dos 28 COREDEs do Rio Grande do Sul, no período de 2000 a 2008, identifica-se que o COREDE Metropolitano Delta do Jacuí se destaca, permanecendo entre os três principais Conselhos do estado, juntamente com os COREDEs Vale do Rio dos Sinos e Serra. O desempenho socioeconômico do Conselho é o reflexo dos resultados apresentados pelos 10 municípios que o compõe. O índice, no período 20002008, passou de 0,791 para 0,808, atingindo a categoria de alto desenvolvimento humano juntamente com o COREDE Serra, cujo IDESE variou de 0,794, em 2000, para 0,814, em 2008, e o COREDE Vale do Rio dos Sinos, que passou de 0,761, em 2000, para 0,789, em 2008. Nos blocos educação, renda e saneamento e domicílio, em 2008, o COREDE Metropolitano Delta do Jacuí também conquistou índices elevados em comparação aos demais Conselhos do estado, como pode ser identificado, respectivamente, a seguir: 0,857 ( $11^{\circ}$ lugar), 0,850 ( $4^{\circ}$ lugar) e 0,684 ( $2^{\circ}$ lugar). Em relação à saúde, contudo, obteve apenas a $23^{\mathrm{a}}$ posição $(0,839)$ (FEE, 2012c).

$\mathrm{Na}$ análise dos municípios que compõem o COREDE Metropolitano Delta do Jacuí, na Tabela 2, é possível observar que, em 1991, todos os integrantes possuíam IDESE no intervalo correspondente à categoria do médio desenvolvimento humano. Os principais destaques, com os maiores índices neste período, foram: Porto Alegre $(0,762)$, Eldorado do Sul $(0,724)$ e Cachoeirinha $(0,716)$. Os municípios de Glorinha $(0,527)$, Santo Antônio da Patrulha $(0,602)$, Viamão $(0,629)$ e Alvorada $(0,631)$ apresentavam resultados para o IDESE inferiores à média estadual $(0,688)$, sendo os municípios com os piores resultados deste Conselho em 1991. 
Tabela 2: IDESE dos Municípios Integrantes do COREDE Metropolitano Delta do Jacuí $1991 / 2000$

\begin{tabular}{|c|c|c|c|c|c|c|c|c|c|c|}
\hline Municípios & $\begin{array}{l}\text { Geral } \\
(1991)\end{array}$ & $\begin{array}{l}\text { Geral } \\
(2000)\end{array}$ & $\begin{array}{c}\text { Educação } \\
\text { (1991) }\end{array}$ & $\begin{array}{c}\text { Educação } \\
\text { (2000) }\end{array}$ & $\begin{array}{l}\text { Renda } \\
\text { (1991) }\end{array}$ & $\begin{array}{l}\text { Renda } \\
(\mathbf{2 0 0 0 )})\end{array}$ & $\begin{array}{c}\text { Saneamento e } \\
\text { Domicílio } \\
(1991)\end{array}$ & $\begin{array}{c}\text { Saneamento e } \\
\text { Domicílio } \\
(2000)\end{array}$ & $\begin{array}{l}\text { Saúde } \\
\text { (1991) }\end{array}$ & $\begin{array}{l}\text { Saúde } \\
\text { (2000) }\end{array}$ \\
\hline Alvorada & 0,631 & 0,699 & 0,730 & 0,811 & 0,482 & 0,503 & 0,531 & 0,656 & 0,780 & 0,826 \\
\hline Cachoeirinha & 0,716 & 0,783 & 0,776 & 0,850 & 0,697 & 0,775 & 0,580 & 0,660 & 0,811 & 0,848 \\
\hline $\begin{array}{c}\text { Eldorado do } \\
\text { Sul }\end{array}$ & 0,724 & 0,706 & 0,726 & 0,807 & 0,794 & 0,698 & 0,545 & 0,434 & 0,829 & 0,886 \\
\hline Glorinha & 0,527 & 0,599 & 0,692 & 0,807 & 0,529 & 0,553 & 0,071 & 0,180 & 0,817 & 0,857 \\
\hline Gravataí & 0,671 & 0,718 & 0,771 & 0,851 & 0,605 & 0,618 & 0,455 & 0,552 & 0,853 & 0,851 \\
\hline Guaíba & 0,677 & 0,707 & 0,765 & 0,851 & 0,623 & 0,600 & 0,495 & 0,533 & 0,824 & 0,842 \\
\hline Porto Alegre & 0,762 & 0,819 & 0,806 & 0,851 & 0,756 & 0,841 & 0,673 & 0,742 & 0,815 & 0,840 \\
\hline $\begin{array}{c}\text { Santo Antônio } \\
\text { da Patrulha }\end{array}$ & 0,602 & 0,656 & 0,720 & 0,815 & 0,611 & 0,638 & 0,231 & 0,315 & 0,845 & 0,854 \\
\hline Triunfo & 0,660 & 0,705 & 0,734 & 0,825 & 0,816 & 0,754 & 0,250 & 0,350 & 0,840 & 0,893 \\
\hline Viamão & 0,629 & 0,701 & 0,750 & 0,822 & 0,488 & 0,532 & 0,474 & 0,594 & 0,803 & 0,858 \\
\hline COREDE & --- & 0,791 & --- & 0,844 & --- & 0,795 & --- & 0,682 & --- & 0,841 \\
\hline Estado & 0,688 & 0,747 & 0,765 & 0,838 & 0,708 & 0,738 & 0,457 & 0,561 & 0,821 & 0,852 \\
\hline
\end{tabular}

Fonte: Elaboração própria a partir de FEE (2012c).

Já a partir do ano de 2000, nota-se uma significativa melhora no IDESE e nos blocos que o compõe, onde todas as cidades deste Conselho, com exceção de Eldorado do Sul, que apresentou crescimento negativo no período de 1991/2000 (-2,49\%), evoluíram positivamente. $\mathrm{O}$ aumento no desenvolvimento verificado nestes municípios, no entanto, não ocorreu de modo homogêneo, ficando os municípios de Glorinha $(13,66 \%)$, de Viamão (11,45\%), de Alvorada (10,78\%), de Cachoeirinha (9,36\%) e de Santo Antônio da Patrulha $(8,97 \%)$ com uma evolução acima da média estadual (8,57\%). Porto Alegre conseguiu atingir a categoria de alto desenvolvimento humano entre os 10 membros do COREDE Metropolitano Delta do Jacuí, passando de um IDESE de 0,762, em 1991, para 0,819, em 2000. Alguns municípios permaneceram com os piores resultados no período, como Glorinha, que passou de 0,527 para 0,599; de Santo Antônio da Patrulha, passando de 0,602 para 0,656; e de Alvorada, que passou de 0,631 para 0,699. Cabe ressaltar que as maiores variações foram verificadas nos municípios que, em 1991, apresentavam os piores resultados para o IDESE.

Entre as maiores evoluções alcançadas neste COREDE, no período de 1991 a 2000, destaca-se aeducação. Neste bloco, o IDESE de Glorinha passou de 0,692 para 0,807, com um crescimento de 16,62\% no período; Santo Antônio da Patrulha passou de 0,720 para 0,815, com um crescimento de 13,20\%; Triunfo passou de 0,734 para 0,825, com um crescimento de 12,40\%; Alvorada passou de 0,730 para 0,811, com um crescimento de 11,09\%; Guaíba passou de 0,765 para 0,851, com um crescimento de 11,24\%; e Eldorado do Sul, que passou de 0,726 para 0,807, com um crescimento de 11,16\%. Cabe destacar que neste bloco, todos os integrantes do COREDE atingiram o alto desenvolvimento humano em 2000. 
Mesmo que se verifique uma melhora relativa entre os dois anos, constata-se a existência de grandes diferenças entre os municípios integrantes deste COREDE, principalmente na dimensãosaneamento e domicílio, que, apesar de ter apresentado crescimento, ainda é onde se verificam as maiores assimetrias entre os municípios. Entre as mais significativas é possível destacar o crescimento obtido pelo município de Glorinha, cuja variação atingiu 153,52\%, passando de um IDESE de 0,071 para 0,180. Mesmo com esta evolução, Glorinha é o integrante com menor IDESE no bloco, possuindo baixo desenvolvimento humano para este quesito. Avanços consideráveis foram verificados, também, nos municípios de Triunfo, que obteve um crescimento de $40 \%$, passando de 0,250 para 0,350; de Santo Antônio da Patrulha, que passou de 0,231 para 0,315, obtendo um crescimento de $36,36 \%$; de Viamão, que passou de 0,474 para 0,594 , com crescimento de 25,32\%; de Alvorada, que passou de 0,531 para 0,656, crescimento de 23,54\%; e de Gravataí, que obteve um crescimento, no período, de 21,32\%, passando de 0,455 para 0,552. Neste bloco, o pior desempenho ficou com Eldorado do Sul, que teve um retrocesso em seu IDESE, passando de 0,545 para 0,434, crescimento de-20,37\%.

Ao analisar os índices referentes à dimensão renda do IDESE, em 1991, nota-se que o único município a atingir o alto desenvolvimento humano foi Triunfo. Porém, em 2000, o município obteve uma queda neste indicador, passando de 0,816, em 1991, para 0,754, em 2000, caindo para a categoria de médio desenvolvimento. Em 2000, somente Porto Alegre atingiu um valor superior a 0,800, cujo resultado passou de 0,756, em 1991, para 0,841, após 10 anos.

Os maiores avanços obtidos pelos integrantes do COREDE Metropolitano Delta do Jacuí ocorreram no bloco saúde, pois, além de apresentarem os maiores resultados entre as dimensões do IDESE, tiveram uma significativa evolução ao final dos 10 anos, sendo que todos os municípios atingiram a classificação de alto desenvolvimento humano. Destaque para os municípios de Eldorado do Sul, que atingiu um crescimento de 6,88\%, passando de 0,829, em 1991, para 0,886, em 2000; de Viamão, que cresceu 6,85\% no período, passando de 0,803, em 1991, para 0,858, em 2000; e de Triunfo, que obteve um crescimento de 6,31\%, passando de 0,840, em 1991, para 0,893, em 2000. A exceção foi o município de Gravataí, que teve uma redução no seu indicador no período, passando de 0,853, em 1991, para 0,851, em $2000(-0,23 \%)$.

Na Tabela 3 é apresentada a evolução do IDESE, geral e blocos, no período mais recente (2001/2008). Estes resultados permitem uma análise atual da situação socioeconômica da população dos municípios que compõe esta região de desenvolvimento. 
Tabela 3: IDESE dos Municípios Integrantes do COREDE Metropolitano Delta do Jacuí 2001/2008

\begin{tabular}{|c|c|c|c|c|c|c|c|c|c|c|}
\hline Municípios & $\begin{array}{l}\text { Geral } \\
(2001)\end{array}$ & $\begin{array}{l}\text { Geral } \\
(2008)\end{array}$ & $\begin{array}{l}\text { Educação } \\
\text { (2001) }\end{array}$ & $\begin{array}{c}\text { Educação } \\
(\text { (2008) }\end{array}$ & $\begin{array}{l}\text { Renda } \\
\text { (2001) }\end{array}$ & $\begin{array}{l}\text { Renda } \\
(\mathbf{2 0 0 8 )}\end{array}$ & $\begin{array}{c}\text { Saneamento e } \\
\text { Domicilio } \\
\text { (2001) }\end{array}$ & $\begin{array}{c}\text { Saneamento e } \\
\text { Domicilio } \\
(\mathbf{2 0 0 8})\end{array}$ & $\begin{array}{l}\text { Saúde } \\
\text { (2001) }\end{array}$ & $\begin{array}{l}\text { Saúde } \\
\text { (2008) }\end{array}$ \\
\hline Alvorada & 0,709 & 0,718 & 0,814 & 0,813 & 0,546 & 0,581 & 0,658 & 0,662 & 0,820 & 0,817 \\
\hline Cachoeirinha & 0,791 & 0,822 & 0,855 & 0,864 & 0,798 & 0,914 & 0,662 & 0,667 & 0,846 & 0,844 \\
\hline $\begin{array}{l}\text { Eldorado do } \\
\text { Sul }\end{array}$ & 0,698 & 0,737 & 0,815 & 0,817 & 0,689 & 0,854 & 0,435 & 0,434 & 0,854 & 0,842 \\
\hline Glorinha & 0,592 & 0,640 & 0,805 & 0,800 & 0,528 & 0,726 & 0,180 & 0,179 & 0,854 & 0,854 \\
\hline Gravataí & 0,725 & 0,755 & 0,851 & 0,864 & 0,638 & 0,739 & 0,553 & 0,556 & 0,856 & 0,860 \\
\hline Guaíba & 0,706 & 0,747 & 0,857 & 0,882 & 0,596 & 0,699 & 0,535 & 0,544 & 0,837 & 0,864 \\
\hline Porto Alegre & 0,819 & 0,834 & 0,855 & 0,866 & 0,840 & 0,889 & 0,744 & 0,750 & 0,838 & 0,833 \\
\hline $\begin{array}{c}\text { Santo Antônio } \\
\text { da Patrulha }\end{array}$ & 0,655 & 0,679 & 0,827 & 0,854 & 0,614 & 0,678 & 0,318 & 0,323 & 0,862 & 0,860 \\
\hline Triunfo & 0,703 & 0,726 & 0,832 & 0,842 & 0,753 & 0,841 & 0,352 & 0,354 & 0,874 & 0,866 \\
\hline Viamão & 0,706 & 0,727 & 0,825 & 0,836 & 0,547 & 0,612 & 0,596 & 0,600 & 0,855 & 0,858 \\
\hline COREDE & 0,792 & 0,808 & 0,847 & 0,857 & 0,795 & 0,850 & 0,685 & 0,684 & 0,841 & 0,839 \\
\hline Estado & 0,750 & 0,772 & 0,841 & 0,853 & 0,748 & 0,819 & 0,564 & 0,570 & 0,848 & 0,846 \\
\hline
\end{tabular}

Fonte: Elaboração própria a partir de FEE (2012c).

Os municípios deste Conselho que conquistaram o alto desenvolvimento humano foram Porto Alegre, que possuía, em 2001, um IDESE de 0,819, tendo atingido já neste ano esta categoria, passou para 0,834, em 2008, e Cachoeirinha, cujo IDESE passou de 0,791, em 2001, para 0,822, em 2008. Os demais integrantes deste Conselho, apesar de terem apresentados resultados superiores aos verificados em 2001 e estando classificados na categoria de médio desenvolvimento humano, tiveram um IDESE inferior à média do Rio Grande do Sul em 2008 (0,772). Permaneceram nas últimas colocações no COREDE Metropolitano Delta do Jacuí os municípios de Glorinha, cujo IDESE passou de 0,592, em 2001, para 0,640, em 2008; de Santo Antônio da Patrulha, que passou de 0,655, em 2001, para 0,679, em 2008; Eldorado do Sul, que passou de um IDESE de 0,698, em 2001, para 0,737, em 2008; e de Alvorada, que passou de 0,709, em 2001, para 0,718, em 2008.

No bloco saúde, pode-se identificar que, apesar de todos os 10 integrantes possuírem resultados superiores a 0,800 , ou seja, alto desenvolvimento humano, a maioria dos municípios obteve crescimento negativo no período de 2001 a 2008. Os retrocessos mais significativos foram observados em Eldorado do Sul $(-1,37 \%)$, que passou de 0,854 , em 2001, para 0,842, em 2008; Triunfo (-0,9\%), que passou de 0,874, em 2001, para 0,866, em 2008; e em Porto Alegre (-0,54\%), que passou de 0,838, em 2001, para 0,833, em 2008. Este desempenho negativo não foi um comportamento somente dos municípios que compõe o COREDE Metropolitano Delta do Jacuí, podendo ser observada uma redução no quesito saúde em todo o Rio Grande do Sul, cujo indicador passou de 0,848, em 2001, para 0,846 , em 2008, ou seja, um crescimento de $-0,26 \%$, podendo ser explicado pela baixa evolução dos índices de saneamento e domicíliono estado, cujo IDESE passou de 0,564, em 2001, para apenas 0,570, em 2008. 
O blocoeducação apresentou os melhores indicadores para todos os 10 integrantes, com exceção de Alvorada (-0,13\%) e Glorinha (-0,63\%), que tiveram crescimento negativo no período. Os municípios que se destacaram por apresentar os melhores resultados foram: Guaíba, que passou de um IDESE de 0,857, em 2001, para 0,882, em 2008; Porto Alegre, que passou de 0,855, em 2001, para 0,866, em 2008; Cachoeirinha, que passou de 0,855, em 2001, para 0,864, em 2008; e Gravataí, que passou de 0,851, em 2001, para 0,864, em 2008 .

Ao analisar os dados referentes ao bloco saneamento e domicílio, pode-se observar que os municípios tiveram pequeno avanço neste período, inclusive no Rio Grande do Sul o crescimento apresentado foi de apenas 1,12\%, passando de 0,564, em 2001, para 0,570, em 2008. Nota-se que para esta dimensão, nenhum município está classificado no alto desenvolvimento humano. Os municípios mais bem posicionados são: Porto Alegre $(0,750)$, Cachoeirinha $(0,667)$ e Alvorada $(0,662)$. Glorinha destaca-se negativamente não só por ocupar a última colocação entre os 10 integrantes deste Conselho, mas por ter apresentado crescimento negativo no período analisado (-0,86\%), passando de um IDESE de 0,180, em 2001, para 0,179, em 2008. Além de Glorinha, estão classificados na categoria de baixo desenvolvimento humano os municípios de Santo Antônio da Patrulha $(0,323)$, de Triunfo $(0,354)$ e de Eldorado do Sul $(0,434)$.

Em relação ao blocorenda, todos os integrantes do COREDE Metropolitano Delta do Jacuí apresentaram incremento na renda de seus munícipes. As maiores variações no nível de renda foram verificadas em Glorinha (37,68\%), passando de 0,528, em 2001, para 0,726, em 2008; Eldorado do Sul, com crescimento de 23,96\%, passando de 0,689, em 2001, para 0,854, em 2008; Guaíba, que passou de 0,596, em 2001, para 0,699, em 2008 (17,29\%); e Gravataí, com um crescimento de $15,85 \%$ no mesmo período, passando de 0,638, em 2001, para 0,739, em 2008. Triunfo, Cachoeirinha, Eldorado do Sul e Porto Alegre foram os únicos integrantes do Conselho a terem atingido o alto desenvolvimento humano, estando os demais municípios classificados no médio desenvolvimento.

Apos verificar a evolução socioeconômica do COREDE Metropolitano Delta do Jacuí e dos municípios que o integram por meio do IDESE, a próxima subseção destina-se a uma análise da evolução dos PIB's dos municípios que compõem o Conselho. 


\subsection{Evolução dos PIB's nos municípios integrantes do COREDE Metropolitano Delta do Jacuí}

A análise da evolução do PIB dos municípios integrantes do COREDE, no período de 1985 a 2008, permite observar que a maioria obteve crescimento econômico, com exceção de Eldorado do Sul (-44\%) e de Guaíba (-11\%). O município de Santo Antônio da Patrulha, apesar de um crescimento de $18 \%$ no período, apresentou uma evolução pouco significativa quando comparado aos demais integrantes do COREDE. Pode-se notar que Glorinha atingiu a maior evolução do PIB no COREDE, crescendo 573\%. Outros municípios que se destacaram, por obter uma variação significativa no mesmo período, foram: Cachoeirinha (210\%), Viamão (200\%), Gravataí (126\%) e Triunfo (105\%) (Tabela $4)$.

Tabela 4: Evolução dos PIB's nos Municípios Integrantes do COREDE Metropolitano Delta do Jacuí - 1985/1996/1999-2008

\begin{tabular}{c|c|c|c|c|c|c|c|c|c|c|c|c|c}
\hline Município/Ano & $\mathbf{1 9 8 5}$ & $\mathbf{1 9 9 6}$ & $\mathbf{1 9 9 9}$ & $\mathbf{2 0 0 0}$ & $\mathbf{2 0 0 1}$ & $\mathbf{2 0 0 2}$ & $\mathbf{2 0 0 3}$ & $\mathbf{2 0 0 4}$ & $\mathbf{2 0 0 5}$ & $\mathbf{2 0 0 6}$ & $\mathbf{2 0 0 7}$ & $\mathbf{2 0 0 8}$ & $\begin{array}{c}\mathbf{1 9 8 5}-\mathbf{2 0 0 8} \\
\text { Variação(\%) }\end{array}$ \\
\hline Alvorada & 100 & 92 & 125 & 133 & 141 & 151 & 145 & 147 & 155 & 158 & 165 & 176 & 76 \\
\hline Cachoeirinha & 100 & 114 & 199 & 207 & 215 & 224 & 239 & 264 & 260 & 254 & 277 & 310 & 210 \\
\hline Eldorado do Sul & - & 100 & 77 & 96 & 92 & 86 & 97 & 108 & 100 & 109 & 74 & 56 & -44 \\
\hline Glorinha & - & 100 & 121 & 133 & 156 & 180 & 217 & 354 & 390 & 441 & 619 & 673 & 573 \\
\hline Gravataí & 100 & 103 & 105 & 123 & 158 & 160 & 157 & 179 & 182 & 187 & 222 & 226 & 126 \\
\hline Guaíba & 100 & 45 & 62 & 52 & 51 & 54 & 53 & 55 & 75 & 86 & 87 & 89 & -11 \\
\hline Porto Alegre & 100 & 139 & 114 & 114 & 112 & 116 & 110 & 111 & 122 & 123 & 130 & 131 & 31 \\
\hline Santo Antônio da Patrulha & 100 & 65 & 82 & 83 & 85 & 92 & 96 & 96 & 93 & 94 & 102 & 118 & 18 \\
\hline Triunfo & 100 & 113 & 150 & 220 & 184 & 209 & 221 & 273 & 269 & 235 & 230 & 205 & 105 \\
\hline Viamão & 100 & 176 & 214 & 229 & 237 & 260 & 269 & 276 & 281 & 284 & 289 & 300 & 200 \\
\hline
\end{tabular}

Fonte: Elaboração própria a partir de IPEADATA (2012).

Notas: (1) PIB Municipal - R\$ de 2000 (mil) - Deflator Implícito do PIB nacional; (2) Os dados têm como base 1985=100, com exceção as cidades de Eldorado do Sul e de Glorinha que têm sua base no ano de 1996; (3) Os dados do ano de 1991 não estavam disponíveis e, para se ter uma referência anterior, foi utilizado o ano de 1985 .

O crescimento econômico ocorrido na maioria dos municípios que compõem o COREDE Metropolitano Delta do Jacuí, apesar de ter propiciado uma melhora nos resultados do IDESE em 2008, não refletiu numa evolução na mesma proporção à obtida no PIB em 2008. No caso de Glorinha, pode-se verificar que apesar de ter crescido 573\% no período de 1985 a 2008, não conseguiu atingir o patamar de alto desenvolvimento, passando de um IDESE de 0,592, em 2001, para apenas 0,640, em 2008. Da mesma forma, Viamão passou de um IDESE de 0,706, em 2001, para 0,727, em 2008, permanecendo na categoria de médio desenvolvimento humano, sendo que atingiu um crescimento de $200 \%$ em seu PIB entre 1985 e 2008. Situação semelhante ocorreu com Gravataí e Triunfo, que mesmo com um crescimento de $126 \%$ e $105 \%$ no PIB no mesmo período, respectivamente, não conseguiram atingir um IDESE superior a 0,800 , ficando com seu indicador em 0,755 
e 0,726, respectivamente, em 2008. Dos municípios que obtiveram um crescimento superior a 100\%, somente Cachoeirinha conseguiu atingir o patamar de alto desenvolvimento, passando de um IDESE de 0,791, em 2001, para 0,822, em 2008. Outro fato que chama a atenção é o de que os municípios de Eldorado do Sul e de Guaíba, apesar de terem apresentado um crescimento negativo em seu PIB, entre 1985 e 2008, não tiveram reflexo negativo no desempenho de seu IDESE, tendo seus indicadores, passando de 0,698 e 0,706, em 2001, para 0,737 e 0,747, em 2008, respectivamente.

Nesta subseção, foi analisada a evolução dos PIB's dos municípios situados na região compreendida pelo COREDE Metropolitano Delta do Jacuí com o intuito de identificar se os avanços alcançados nos indicadores de desenvolvimento humano e social podem estar relacionados à melhoria da renda do município.

\subsection{Gastos sociais nos municípios integrantes do COREDE Metropolitano Delta do Jacuí}

Nesta subseção são analisados os gastos sociais das Prefeituras dos municípios que compõem o COREDE Metropolitano Delta do Jacuí, de 1995 a 2008, buscando identificar se a evolução destes gastos pode estar associada ao desempenho apresentado nos índices de desenvolvimento socioeconômico atuais destes municípios. Na Tabela 5 pode ser observado que, ao final do período analisado, todos os governos municipais expandiram, significativamente, o volume de gastos destinados ao atendimento das demandas sociais de seus munícipes.

Tabela 5: Evolução dos Gastos Sociais com Assistência Social, Saúde, Saneamento, Educação e Cultura nos Municípios Integrantes do COREDE Metropolitano Delta do Jacuí $-1995-2008$

\begin{tabular}{c|c|c|c|c|c|c|c|c|c|c|c|c|c|c|c}
\hline Discriminação & $\mathbf{1 9 9 5}$ & $\mathbf{1 9 9 6}$ & $\mathbf{1 9 9 7}$ & $\mathbf{1 9 9 8}$ & $\mathbf{1 9 9 9}$ & $\mathbf{2 0 0 0}$ & $\mathbf{2 0 0 1}$ & $\mathbf{2 0 0 2}$ & $\mathbf{2 0 0 3}$ & $\mathbf{2 0 0 4}$ & $\mathbf{2 0 0 5}$ & $\mathbf{2 0 0 6}$ & $\begin{array}{c}\mathbf{2 0 0 7} \\
\mathbf{2 0 0 8}\end{array}$ & $\begin{array}{c}\mathbf{1 9 9 5 - 2 0 0 8} \\
\text { Variação } \\
(\mathbf{\%})\end{array}$ \\
\hline Alvorada & 100 & 109 & 108 & 141 & 149 & 168 & - & 180 & 183 & 196 & 209 & 246 & 246 & 305 & 205 \\
\hline Cachoeirinha & 100 & 113 & 113 & 164 & 190 & 188 & 182 & 204 & 194 & 232 & 232 & 295 & 318 & 382 & 282 \\
\hline Eldorado do Sul & 100 & 102 & 96 & 151 & 155 & 191 & 187 & 170 & 172 & 231 & 241 & 314 & 260 & 311 & 211 \\
\hline Glorinha & 100 & 94 & 94 & 110 & 185 & 165 & 217 & 205 & 166 & 298 & 293 & 337 & 315 & 500 & 400 \\
\hline Gravataí & 100 & 117 & 123 & 158 & 195 & 218 & 199 & 185 & 172 & 214 & 236 & 327 & 377 & 458 & 358 \\
\hline Guaíba & 100 & 99 & 91 & 122 & 128 & 145 & 163 & 195 & 166 & 154 & 160 & 202 & 299 & 293 & 193 \\
\hline Porto Alegre & 100 & 126 & 181 & 193 & 182 & 186 & 193 & 161 & 113 & 163 & 164 & 181 & 202 & 216 & 116 \\
\hline $\begin{array}{c}\text { Santo Antônio } \\
\text { Patrulha }\end{array}$ & 100 & 105 & 95 & 130 & 131 & 121 & 125 & 143 & 155 & 156 & 155 & 173 & 181 & 228 & 128 \\
\hline Triunfo & 100 & 100 & 101 & 108 & 115 & - & 128 & 180 & 173 & 172 & 168 & 210 & 276 & 333 & 233 \\
\hline Viamão & 100 & 140 & 118 & 206 & 240 & 256 & 271 & 285 & 290 & 279 & 340 & 391 & 463 & 414 & 314 \\
\hline
\end{tabular}

Fonte: Elaboração própria a partir de TCE-RS (2012) para os dados de 2004-2008; e Rückert et al. (2008) para os anos de 1995 a 2003.

Notas: (1) Os dados têm como base 1995=100. (2) Não há informações para Triunfo em 2000 e para Alvorada em 2001. 
Nota-se que a maior expansão dos gastos sociais ocorreu em Glorinha, com uma variação de $400 \%$, que pode estar associada ao crescimento do PIB deste município, destacado na subseção anterior, onde obteve a maior variação do COREDE (573\%). O segundo maior crescimento apresentado nos gastos sociais foi verificado em Gravataí, atingindo uma variação de $358 \%$ no período. Cabe destacar que o município foi o que obteve o quarto maior crescimento do PIB no Conselho, atingindo uma variação de $126 \%$. Viamão e Cachoeirinha apresentaram um significativo crescimento nos gastos sociais, no mesmo período, atingindo 314\% e 282\%, respectivamente. Já Porto Alegre, Santo Antônio da Patrulha e Guaíba, apesar de terem ampliado o volume de gastos sociais entre 1995 e 2008, em relação aos demais municípios, foram os integrantes que apresentaram as menores variações, atingindo um crescimento de apenas 116\%, 128\% e 193\%, respectivamente. Nota-se, também, como apresentado na subseção anterior, que Guaíba teve um recuo de $11 \%$ em seu PIB, no período de 1985 a 2008. Porto Alegre e Santo Antônio da Patrulha também estão entre os municípios que tiveram as menores variações em seu PIB, $31 \%$ e $18 \%$, respectivamente, no período.

A ampliação dos gastos públicos, realizada pelos municípios que compõem o COREDE Metropolitano Delta do Jacuí, não aconteceu de forma homogênea, sendo possível verificar uma grande expansão nos municípios de Glorinha, de Gravataí, de Viamão, de Cachoeirinha e de Alvorada. Por outro lado, houve municípios com uma evolução dos gastos não tão expressiva, como em Porto Alegre, em Santo Antônio da Patrulha e em Guaíba.

Apesar da ampliação dos gastos sociais ter proporcionado uma melhora nos resultados do IDESE em 2008, no entanto, não houve uma evolução proporcional à taxa de expansão dos gastos públicos nos municípios. No caso de Glorinha, pode-se verificar que apesar de ter crescido 400\% no período de 1995 a 2008, não conseguiu atingir o patamar de alto desenvolvimento, passando de um IDESE de 0,592, em 2001, para apenas 0,640, em 2008, permanecendo na última posição no COREDE.Situação semelhante ocorreu com Gravataí, que atingiu um IDESE de apenas 0,755, em 2008, ante 0,725, em 2001, permanecendo na categoria de médio desenvolvimento humano, sendo que houve um crescimento de $358 \%$ nos seus gastos sociais entre 1995 e 2008. Viamão, mesmo com um aumento de $314 \%$ nos seus gastos sociais, não conseguiu atingir um IDESE superior a 0,800, ficando com seu indicador em 0,727, em 2008. Dos municípios que tiveram grande expansão do gasto social, somente Cachoeirinha conseguiu atingir o alto desenvolvimento humano, obtendo um IDESE de 0,822, em 2008. Cabe lembrar que Porto Alegre já havia 
atingido o alto desenvolvimento humano em 2000, com um IDESE de 0,819, passando para 0,834 , em 2008 .

Examinando-se a evolução dos gastos sociais e comparando-a com a melhoria do IDESE nas dimensões saneamento e domicílio, educação e saúde, se pode observar que apesar de Glorinha (400\%), Gravataí (358\%), Viamão (314\%), Cachoeirinha (282\%) e de Alvorada (205\%) apresentarem as maiores expansões no montante de recursos destinados às políticas sociais, estedesempenho não se refletiu de forma direta nos indicadores de desenvolvimento humano e social de seus munícipes. Nota-se que Glorinha, mesmo obtendo um crescimento de $400 \%$ nos gastos sociais no período 1995-2008, na dimensão educação passou de um IDESE de 0,805, em 2001, para 0,800, em 2008, possuindo o pior resultado entre os 10 integrantes deste Conselho.No bloco saneamento e domicílio, passou de um IDESE de 0,180, em 2001, para 0,179, em 2008 (último lugar). Já na dimensão saúde manteve, em 2008, o mesmo resultado obtido em 2001, com um IDESE de 0,854 (sexto lugar), sua melhor colocação. Gravataí, que teve um crescimento de $358 \%$ nos gastos sociais, apresentou para o bloco saneamento e domicílio um IDESE de 0,556, em 2008, ocupando o quinto lugar no ranking dos municípios que compõem este Conselho. Já para a dimensão educação, o município obteve um IDESE de 0,864, em 2008, ou seja, a quarta melhor colocação, e para a dimensão saúde apresentou o terceiro melhor resultado, com um IDESE de 0,860, em 2008. Viamão, com uma variação de $314 \%$ nos gastos sociais, obteve sua melhor colocação no bloco saneamento e domicílio, com um IDESE de 0,600, em 2008, permanecendo na quarta colocação; na dimensão educação, atingiu apenas o sétimo lugar, com um IDESE de 0,836, em 2008; já para a dimensão saúde, apresentou um IDESE de 0,858, em 2008, atingindo o quinto melhor resultado.

No que se refere somente aos gastos municipais na área de educação, como se observa na Tabela 6 , Glorinha se destaca como o município que teve o maior crescimento entre 2000 e 2008, apresentando uma variação de 479,30\%, seguida de Alvorada, que evoluiu 261,44\% no mesmo período. O município de Porto Alegre teve o maior gasto em valores absolutos em educação no ano de 2008, R\$ 395 milhões, contudo, alcançou a menor variação nos gastos no período, 100,63\%. 
Tabela 6: Variação dos Gastos com Educação nos Municípios Integrantes do COREDE Metropolitano Delta do Jacuí - 2000/2008

\begin{tabular}{c|c|c|c}
\hline Municípios & Educação e Cultura (R\$) - 2000 & Educação (R\$) - 2008 & Variação Educação (\%) \\
\hline Alvorada & $11.901 .838,96$ & $43.018 .578,13$ & 261,44 \\
\hline Cachoeirinha & $12.814 .256,51$ & $39.080 .154,63$ & 204,97 \\
\hline Eldorado do Sul & $5.697 .548,36$ & $17.552 .594,72$ & 208,07 \\
\hline Glorinha & $725.128,45$ & $4.200 .704,74$ & 479,30 \\
\hline Gravataí & $36.215 .699,73$ & $88.540 .918,25$ & 144,48 \\
\hline Guaíba & $9.971 .679,50$ & $25.786 .568,88$ & 158,60 \\
\hline Porto Alegre & $197.119 .580,16$ & $395.471 .503,40$ & 100,63 \\
\hline Santo Antônio da Patrulha & $3.470 .517,76$ & $11.646 .195,16$ & 235,58 \\
\hline Triunfo & - & $44.228 .186,86$ & - \\
\hline Viamão & $18.191 .111,74$ & $56.298 .571,80$ & \\
\hline
\end{tabular}

Fonte: Elaboração própria a partir de TCE-RS (2012).

Notas: (1) Dados expressos em valores nominais. (2) Triunfo não teve dados disponibilizados em 2000.

Segundo INEP (2012), o Rio Grande do Sul tinha 1.740.723 de alunos matriculados no Ensino Fundamental em 2000 e, em 2008, esse número caiu para 1.598 .403 alunos (8,18\%). Entre os municípios que fazem parte do COREDE Metropolitano Delta do Jacuí, Glorinha foi o que registrou o maior aumento de matrículas nesta modalidade de ensino, crescendo 21,16\%. Na Tabela 7 é possível observar esta evolução.

Tabela 7: Número de Alunos Matriculados nos Municípios Integrantes do COREDE Metropolitano Delta do Jacuí - 2000/2008

\begin{tabular}{|c|c|c|c|c|c|c|c|}
\hline Município & $\begin{array}{c}\text { Ensino } \\
\text { Fundamental } \\
(\mathbf{2 0 0 0 )}\end{array}$ & $\begin{array}{c}\text { Ensino } \\
\text { Fundamental } \\
(\mathbf{2 0 0 8})\end{array}$ & $\begin{array}{c}\text { Ensino Médio } \\
\text { (2000) }\end{array}$ & $\begin{array}{c}\text { Ensino Médio } \\
\text { (2008) }\end{array}$ & $\begin{array}{c}\text { Educação de } \\
\text { Jovens e } \\
\text { Adultos (2000) }\end{array}$ & $\begin{array}{c}\text { Educação de } \\
\text { Jovens e } \\
\text { Adultos (2008) }\end{array}$ & $\begin{array}{c}\text { Educação } \\
\text { Profissional } \\
\text { Nível Técnico } \\
\text { (2008) }\end{array}$ \\
\hline Cachoeirinha & 19.482 & 18.869 & 6.800 & 6165 & 4.088 & 2371 & 1440 \\
\hline Eldoradodo Sul & 4.866 & 5.637 & 463 & 1216 & 1.370 & 714 & 0 \\
\hline Glorinha & 865 & 1.048 & 205 & 270 & 158 & 101 & 0 \\
\hline Porto Alegre & 218.281 & 191.891 & 66.482 & 53600 & 46.366 & 29212 & 14367 \\
\hline $\begin{array}{l}\text { Santo Antônio da } \\
\text { Patrulha }\end{array}$ & 5.829 & 5.619 & 1.658 & 1482 & 489 & 686 & 0 \\
\hline Triunfo & 4.222 & 4.261 & 768 & 1415 & 1.126 & 636 & 410 \\
\hline Viamão & 39.600 & 42.018 & 7.793 & 9107 & 4.234 & 4258 & 361 \\
\hline Rio Grande do Sul & 1.740 .723 & 1.598 .403 & 465.882 & 429349 & 251.489 & 178407 & 80661 \\
\hline
\end{tabular}

Fonte: Elaboração própria partir de INEP (2012).

Notas: (1) Número total de matrículas em escolas municipais, estaduais e privadas. (2) Para o ano de 2000, o INEP não apresentou dados das matrículas referentes à Educação Profissional de Nível Técnico.

Além de Glorinha, apenas mais quatro municípios registraram aumento nas matrículas do Ensino Fundamental: Eldorado do Sul (15,84\%), Alvorada (7,64\%), Viamão $(6,11 \%)$ e Triunfo $(0,92 \%)$. Os demais municípios, assim como o estado, tiveram um crescimento negativo e Guaíba foi o que apresentou maior redução no número de matrículas, 12,66\%. Na modalidade do Ensino Médio, que atende alunos com faixa etária entre 15 e 17 anos, o número de cidades com aumento nas matrículas foi superior ao Ensino Fundamental, em 2008. Os municípios com taxas de crescimento mais expressivas foram Eldorado do Sul (162,63\%), Triunfo (84,24\%)e Alvorada (33,33\%). A taxa de crescimento para o Rio Grande do Sul, para o Ensino Médio, foi negativa $(-7,84 \%)$, 
semelhante à registrada no Ensino Fundamental. Outros municípios, como Guaíba, Porto Alegre e Santo Antônio da Patrulha repetiram seus índices negativos em relação ao número de alunos matriculados, com $-20,84 \%,-19,38 \%$ e $-10,62 \%$, respectivamente. A matrícula para a modalidade de Ensino para Jovens e Adultos, que visa atender aquelas pessoas que não completaram o Ensino Fundamental e Médio em idade escolar, registrou queda em seu número na maioria dos municípios do COREDE Metropolitano Delta do Jacuí entre 2000 e 2008. Os municípios que registraram taxas positivas foram apenas Santo Antônio da Patrulha (40,29\%), Alvorada (3,12\%) e Viamão (0,57\%). As cidades com maior declínio no número de matrículas foram Eldorado do Sul (-47,88\%), Triunfo (-43,52\%) e Cachoeirinha (-42,00\%). Por fim, na modalidade de Educação Profissional, não há dados de alunos matriculados em 2000, talvez pelo motivo de a União somente em 2005 criar programas que ampliam a formação profissional dos jovens no país. Em 2008, Porto Alegre foi o município com maior número de alunos matriculados, 14.367 matrículas, muito provavelmente por ter a maior densidade demográfica entre as cidades do Conselho.

É possível observar que o número de matrículas reduziu-se na maioria dos municípios. Esta redução pode estar associada à evasão escolar e à necessidade de ingresso no mercado de trabalho para aqueles jovens que pertencem às famílias com baixos rendimentos. Contudo, apesar da redução no número de matrículas, os municípios apresentaram evolução do índice de educação, já que todos se enquadram no alto nível de desenvolvimento educacional, de acordo com o IDESE, em 2008. Sendo assim, é possível supor que este melhor desempenho está ligado à competência dos municípios em fomentar a educação do ensino infantil e fundamental.

Nesta seção foi possível analisar a evolução socioeconômica dos municípios que compõem o COREDE Metropolitano Delta do Jacuí, por meio dos resultados obtidos por estes integrantes no IDESE, bem como a expansão verificada no PIB e nos gastos sociais destes municípios. Nota-se que as administrações municipais desta região estão despendendo um montante maior de recursos para as áreas sociais, principalmente nas cidades mais populosas, tendo em vista que possuem um contingente populacional maior acessando os serviços disponibilizados nas áreas da educação, saúde e assistência social, dentre outras.

A partir dos dados brutos de gastos sociais analisados, entretanto, não é possível discriminar adequadamente os gastos com saúde e com saneamento. Com o objetivo de atender os percentuais estabelecidos pela Lei de Responsabilidade Fiscal de aplicação da receitatributária em saúde, muitos estados e municípios, incluindo os do COREDE 
Metropolitano Delta do Jacuí, registram gastos em saneamento e outros de forma agregada com os dispêndios com saúde. Esta situação é, de tal modo, generalizada, que recentemente foi sancionada a Emenda 29 à Lei de Responsabilidade Fiscal, que impede que o pagamento de aposentadorias e pensões dos servidores de saúde, as obras de saneamento básico ou ações de limpeza urbana, entre outros, sejam considerados para fins de cálculo dos gastos em saúde (EMENDA, 2012). Já em relação aos gastos com educação, foi possível uma análise mais detalhada, pois os mesmos se mostram mais condizentes em sua aplicação.

Por fim, os gastos sociais municipais correspondem a uma parcela pequena dos gastos sociais públicos globais. As transferências dos estados e, sobretudo, da União desempenham papel muito significativo nos dispêndios públicos com educação e saúde. Uma análise mais completa exigiria contemplar também estes gastos em cada município, o que ampliaria muito o escopo da análise e extrapolaria os limites deste estudo. Entretanto, ainda que relativamente modestos frente aos gastos totais estatais com saúde e educação, os gastos municipais desempenham papel fundamental na medida em que contemplam a educação inicial e grande parte do primeiro atendimento de saúde, servindo como bases para as ações dos estados e da União.

\section{CONSIDERAÇÕES FINAIS}

A preocupação com os efeitos dos gastos públicos na economia tem sido uma constante dos gestores, principalmente com os impactos no crescimento econômico, na qualidade de vida da população e seus reflexos na redução da pobreza. Cabe ressaltar, também, que o conjunto da população espera uma melhor utilização dos recursos públicos, pois existem limites orçamentários e financeiros para a expansão das receitas que financiam o aumento dos gastos per capita.

Com a instituição dos COREDEs, o estado do Rio Grande do Sul procurou a promoção do desenvolvimento regional, harmônico e sustentável por meio de uma maior integração dos recursos e das ações governamentais nas diferentes regiões. Desta forma, os governos buscam retornar os tributos arrecadados dos contribuintes por meio de serviços públicos e de políticas públicas que permitam uma redistribuição de recursos mais adequada. Estas políticas são desenvolvidas com a intenção de reduzir a pobreza e dar condições de vida mais dignas à população, priorizando o cumprimento do conjunto de metas estabelecidas nas conferências mundiais da ONU. No entanto, os recursos 
disponíveis pelo poder público para o custeio de suas atividades, bem como para a realização de investimentos e de implementação de políticas públicas, são escassos.

Neste contexto, analisou-se, neste artigo, o IDESE, que é utilizado como medidaresumo do desenvolvimento humano, social e econômico no Rio Grande do Sul, bem como as características socioeconômicas dos municípios integrantes do COREDE Metropolitano Delta do Jacuí. Apesar das disparidades existentes entre os municípios deste COREDE, dependendo da área analisada, viu-se que seus integrantes obtiveram uma melhora considerável em seus indicadores de desenvolvimento. Os municípios que atingiram o alto desenvolvimento humano, em 2008, foram Porto Alegre e Cachoeirinha. Os demais integrantes deste Conselho, apesar de terem apresentados resultados superiores aos verificados em 1991 e estando classificados na categoria de médio desenvolvimento humano, atingiram um IDESE inferior à média do $\operatorname{COREDE}(0,808)$ e do Rio Grande do Sul (0,763), em 2008. Os municípios de Glorinha e de Santo Antônio da Patrulha permaneceram nas últimas posições no COREDE Metropolitano Delta do Jacuí.

Das dimensões que compõem o IDESE, a área da educação é a que apresentou os melhores resultados, seguida desaúde e renda. Os resultados referentes à dimensão saneamento e domicílio demonstram que a maioria dos municípios obteve índices baixos, atingindo pequenos avanços neste período, onde, inclusive, o Rio Grande do Sul apresentou um discreto crescimento de 24,73\%, no período, passando para 0,570, em 2008. Nota-se que para este componente, nenhum município está classificado no alto desenvolvimento humano. Os municípios mais bem posicionados, em 2008, são: Porto Alegre $(0,758)$, Cachoeirinha $(0,667)$ e Alvorada (0,662). Glorinha destaca-se negativamente por ocupar a última colocação entre os 10 integrantes deste Conselho $(0,179)$. Além de Glorinha, estão classificados na categoria de baixo desenvolvimento humano os municípios de Eldorado do Sul $(0,434)$, de Santo Antônio da Patrulha $(0,323)$ e de Triunfo $(0,354)$.

De acordo com este estudo foi possível diagnosticar que os municípios que apresentaram maior expansão do gasto social, bem como crescimento do PIB, não estão, necessariamente, entre os municípios que possuem os melhores índices de desenvolvimento humano. Portanto, constata-se que os índices mais recentes do IDESE são superiores àqueles alcançados pelos municípios do COREDE em 1991, mostrando que houve avanço no período analisado em todas as dimensões, porém observou-se que apesar de terem despendido um montante maior de recursos para as áreas sociais e das melhorias obtidas nos seus indicadores socioeconômicos e de desenvolvimento humano, 
principalmente na dimensão educação, as demais áreas analisadas não demonstram serem sensíveis somente às variações dos gastos sociais e dos PIB's municipais. Desta forma, a explicação para os municípios que possuem melhores índices de desenvolvimento humano e socioeconômico deve-se também a outros fatores que não somente aos gastos públicos e à variação da renda destes.

Sendo assim, sugere-se que novas pesquisas incluam outras variáveis explicativas, como, por exemplo, os gastos e os investimentos realizados diretamente pelo estado e pela União nos municípios, bem como de que forma a atuação social das empresas privadas interfere na melhoria da qualidade de vida da população.

\section{REFERÊNCIAS BIBLIOGRÁFICAS}

BISPO, R. S. IDH de Roraima:condicionantes e especificidades. Roraima: UFRR, 1999.Disponível em: <http://www.ufrr.br>. Acesso em: 05 set. 2009.

EMENDA que fixa gastos da União com saúde pública é sancionada com 15 vetos. Clipping FENASPS, Brasília, 17 jan. 2012. Disponível em:

<www.fenasps.org.br/noticias/170112clipping.pdf>. Acesso em: 9 abr. 2012.

FUNDAÇÃO DE ECONOMIA E ESTATÍSTICA. FEE. FEEDados. Disponível em: <http://www.fee.rs.gov.br/feedados/consulta/sel_modulo_pesquisa.asp>. Acesso em: 03 mar. 2012b.

FUNDAÇÃO DE ECONOMIA E ESTATÍSTICA. FEE. Índice de Desenvolvimento Socioeconômico. Disponível em:

<http://www.fee.rs.gov.br/sitefee/pt/content/estatisticas/pg_idese.php>. Acesso em: 12 mar. 2012c.

FUNDAÇÃO DE ECONOMIA E ESTATÍSTICA. FEE. Resumo estatístico. Disponível em: <http://www.fee.tche.br/sitefee/pt/content/resumo/index.php>. Acesso em: 03 mar. 2012a.

FERNANDES, M. A. C. et al. Gasto social nas três esferas de governo - 1995. Brasília: IPEA, 1998.

GIACOMONI, J. Orçamento público. $7^{\mathrm{a}}$ ed. São Paulo: Atlas, 1998.

GIAMBIAGI, F.; ALÉM, A.C.D. Finanças públicas. $2^{\text {a }}$ ed. Rio de Janeiro: Campus, 2000. 
INEP. INSTITUTO NACIONAL DE ESTUDOS E PESQUISAS EDUCACIONAIS ANÍSIO TEIXEIRA. Disponível em: <http://inep.gov.br>. Acesso em: 15 mar. 2012.

IPEADATA. INSTITUTO DE PESQUISA ECONÔMICA APLICADA. Base de dados regionais/contas nacionais. Disponível em: <www.ipeadata.gov.br>. Acesso em: 5 mar. 2012.

OLIVEIRA, D. P. R. Sistemas de informações gerenciais. $4^{\text {a }}$ ed. São Paulo: Atlas, 1999. OSBONE, D.; GAEBLER, T. Reinventando o governo: como o espírito empreendedor está transformando o setor público. $4^{\text {a }}$ ed. Brasília: MH Comunicação, 1994.

REZENDE, A. J. et al. A gestão pública municipal e a eficiência dos gastos públicos: uma investigação empírica entre as políticas públicas e o IDH. Revista Universo Contábil, Blumenau, n.1, p.24, jan/abr.2005.

RÜCKERT, I. et al. Finanças públicas e gastos sociais nos municípios do RS: 1995 2003. Porto Alegre: FEE 2008. (Documentos FEE, n.41).

SECRETARIA DE PLANEJAMENTO, GESTÃO E PARTICIPAÇÃO CIDADÃ. SEPLAG. Regiões funcionais de planejamento e COREDEs. Disponível em: $<$ http://www.seplag.rs.gov.br/conteudo_puro.asp?cod_menu_pai=\&cod_tipo_conteudo=\& cod_menu=492>. Acesso em: 15 mar. 2012.

SLOMSKI, V. Teoria do agenciamento no Estado: uma evidência da distribuição de renda econômica produzida pelas entidades públicas de administração direta. Tese (Doutorado em Controladoria e Contabilidade) - Universidade de São Paulo, São Paulo, 1999.

SOUZA, H. Empresa pública e cidadã. Folha de São Paulo, São Paulo, 26 mar. 1997. TRIBUNAL DE CONTAS DO RIO GRANDE DO SUL. TCE-RS. 2010. Disponível em: <http://www.tce.rs.gov.br >. Acesso em: 18 mar. 2012. 